95 per cent alcohol. The occlusion of other organic acids with precipitated pectin bodies and cream of tartar makes the use of only $50 \mathrm{cc}$. of grape juice advisable for the determination.

In case of syrups, fermentation of sugar or a separa. tion of the acid therefrom as the lead salt ${ }^{1}$ is advisable. It may be of interest to mention that Halenke and Mölinger advise a double precipitation in the case of grape juices.

FOR ARTIFICIAL PRODUCTS CONTAINING FREE PHOSPHORIC ACID AND ALCOHOL-While experimenting with synthetic solutions, containing tartaric acid, free phosphoric acid and alcohol, it was found that neither the Halenke-Möslinger method nor the Hartmann and Eoff method gave satisfactory results. Further, it developed that these two methods became less reliable as the solutions under discussion aged. This condition was found to be brought about by the formation of ethyl esters of tartaric acid, the amount of ester formed increasing with the time allowed for the reaction. This was shown by saponifying the solution with an excess of alkali before determining the tartaric acid, a complete recovery of the theoretical a mount of acid being thereby obtained. It was also observed that in cases where much free phosphoric acid was present the Halenke and Möslinger method failed to give any precipitate of potassium acid tartrate whatever, notwithstanding the presence of considerable tartaric acid in the solution. These two points, the loss of tartaric acid through esterification and the failute of the Halenke-Moslinger method to give even approximate results in presence of free phosphoric acid, were made the subject of investigation in I9I4 by the Associate Referee on. Wines of the Association of Official Agricultural Chemists. The heretofore unpublished work of five collaborators was very satisfactory and fully substantiates the findings recorded above.

The behavior of alcohol and tartaric acid in the presence of other free organic acids (formation of esters) is a well-known phenomenon and was pointed out by Berthelot and Fleurieu in their original paper describing the alcohol-ether method. Esterification in part may explain why very old wines, when employing the customary methods for determining the total tartaric acid, very often show an exceedingly small amount of this constituent.

It is very important to know the extent of esterification in artificial products containing free phosphoric acid, alcohol, and tartaric acid, since the ordinary methods may not reveal the tartaric acid that is present even in amounts as high as $3 \mathrm{~g}$. per $100 \mathrm{cc}$. of solution.

It was found that by adding $5 \mathrm{cc} . N \mathrm{NaOH}$ in excess of neutralization to $50 \mathrm{cc}$. of the solution under examination, bringing to a boil and allowing to stand over night, a complete saponification could be obtained. The addition of the required amount of tartaric acid, dilution to roo cc. with water and then proceeding as detailed for wines, yielded quantitative results for total tartaric acid.

1 C. Schmitt and C. Hiepe, Z. anal. Chem., 21 (1882), 534-41.
Solutions indicated in Table $V$ were analyzed by different analysts on different dates with the results given.

\begin{tabular}{|c|c|c|c|}
\hline DETERMINATION & $\begin{array}{c}\text { HALENKE AND } \\
\text { MÖSLINGER } \\
\text { METHOD }\end{array}$ & $\begin{array}{c}\text { HARTMANN } \\
\text { Half } \\
\text { Neutralized }\end{array}$ & $\begin{array}{l}\text { EOFF METHOD } \\
\text { Completely } \\
\text { Neutralized }\end{array}$ \\
\hline 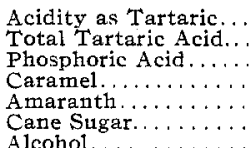 & $\begin{array}{l}4.92 \\
2.00 \\
1.91 \\
1.20 \\
0.024 \\
5.00 \\
5.00\end{array}$ & $\begin{array}{l}2.52 \\
1.80 \\
0.48 \\
1.20 \\
0.024 \\
5.00 \\
5.00\end{array}$ & $\begin{array}{l}1.96 \\
1.89 \\
0.048 \\
1.20 \\
0.024 \\
5.00 \\
5.00\end{array}$ \\
\hline
\end{tabular}

Table VI presents results obtained on three synthetic solutions, on the dates indicated.

\begin{tabular}{|c|c|c|c|c|c|}
\hline Solution & $\begin{array}{l}\text { DATE } \\
1914\end{array}$ & $\begin{array}{c}\text { HALENKE } \\
\text { AND } \\
\text { MÖSLINGER }\end{array}$ & $\begin{array}{l}\text { HAR } \\
\text { Net } \\
\text { Half }\end{array}$ & $\begin{array}{l}\text { MANN AND } \\
\text { ralization } \\
\text { Complete }\end{array}$ & $\begin{array}{l}\text { EOFF METHOD } \\
\text { Preliminary } \\
\text { Saponification }\end{array}$ \\
\hline I. . . & $\begin{array}{r}7 / 20 \\
8 / 12 \\
8 / 24 \\
8 / 26 \\
10 / 30\end{array}$ & $\begin{array}{l}0.74 \\
0.64 \\
0.06 \\
0.63 \\
0.00\end{array}$ & $\begin{array}{l}1.88 \\
1.69 \\
1.54 \\
1.66 \\
1.61\end{array}$ & $\begin{array}{l}1.90 \\
1.84 \\
1.76 \\
1.67 \\
1.65\end{array}$ & $\begin{array}{c}\ldots \\
2.00 \\
\ldots\end{array}$ \\
\hline II ..... & $\begin{array}{r}7 / 20 \\
8 / 12 \\
8 / 24 \\
8 / 26 \\
10 / 30\end{array}$ & $\begin{array}{l}1.03 \\
0.90 \\
0.67 \\
0.91 \\
0.65\end{array}$ & $\begin{array}{l}1.76 \\
1.62 \\
1.51 \\
1.57 \\
1.51\end{array}$ & $\begin{array}{l}1.76 \\
1.68 \\
1.62 \\
1.58 \\
1.63\end{array}$ & $\begin{array}{c}\cdots \\
\cdots \\
1.79 \\
\ldots\end{array}$ \\
\hline III ..... & $\begin{array}{r}7 / 20 \\
8 / 12 \\
8 / 24 \\
8 / 26 \\
10 / 30\end{array}$ & $\begin{array}{l}1.23 \\
1.18 \\
1.00 \\
1.22 \\
0.92\end{array}$ & $\begin{array}{l}1.87 \\
1.77 \\
1.68 \\
1.72 \\
1.63\end{array}$ & $\begin{array}{l}1.87 \\
1.77 \\
1.77 \\
1.71 \\
1.67\end{array}$ & $\begin{array}{c}\ldots \\
1.89 \\
\ldots\end{array}$ \\
\hline
\end{tabular}

The low results obtained by the Halenke and Möslinger method show the necessity of starting the precipitation by stirring as illustrated by the results obtained on August 24th, and October 30 th. The gradual esterification of the free tartaric acid is shown by the lower results obtained as the solutions aged.

BURFAU OF ChEMISTRY, WASHINGTON

\section{THE DECOMPOSITION OF THE ORGANIC MATTER OF KELP IN THE SOIL}

By A. W. Christie

Received November 15, 1915

Considerable interest has been evinced of late in the possible use of kelp as a commercial fertilizer. Burd $^{2}$ has shown that probably the most practical and profitable way of utilizing kelp would consist in drying at a low temperature and grinding. The resulting product, in addition to the valuable potash (I I.45 per cent $\mathrm{K}_{2} \mathrm{O}$ in air-dried kelp (Macrocystis)) contains all the nitrogen and organic matter. Stewart ${ }^{3}$ has shown that the nitrogen (I.I8 per cent $N$ in airdried kelp (Macrocystis)) becomes slowly available in the soil. In connection with the probable use of dried and ground kelp as a commercial fertilizer or as a filler for mixed fertilizers, it becomes of interest to learn the fate of the organic matter and whether any agricultural value may be assigned to it. The extent and rate of decomposition of kelp in soil were compared with the following materials which are common sources of organic matter in the soil, viz. manure, straw and alfalfa.

\section{PLAN OF EXPERIMENT}

In each of I4 glass jars were placed $300 \mathrm{~g}$. of airdried soil (fine sandy loam from Anaheim, California), i See also work of U.S. Department of Agriculture on Kelp. [EDiror's NOTE.]

2 "Economic Value of Pacific Coast Kelps," Bull. 248, California Agricultural Experiment Station.

"Availability of Nitrogen in Pacific Coast Kelps," J. Agr. Research, 4, No. 1 (1915), 21 
and to each jar were added I $5 \mathrm{~g}$. of the organic material to be tested. The two samples of kelp used were Macrocystis pyrifera and Nereocystis leutkeana, the varieties of greatest commercial importance on the Pacific Coast. These samples were oven-dried and finely ground and then allowed to come to constant moisture content by exposure to the air at room temperature. The manure, alfalfa and straw were also finely ground and thoroughly air-dried. Jars I I and $\mathrm{I}_{2}$, in addition to the $\mathrm{I}_{5} \mathrm{~g}$. Macrocystis, were inoctulated with a few cc. of a solution from a jar of decomposing kelp, to ascertain if the partial sterilization due to oven-drying would have any effect on the stibsequent decomposition in the soil. All jars were loosely stoppered to prevent excessive evaporation, yet allowing easy access of air, and were kept at an average temperature of $30^{\circ} \mathrm{C}$. for 5 mos. The moisture content was maintained at is per cent (optinum for the soil) by frequent additions of sterile water, accompanied by cultivation of the soil.

At the end of 5 mos. the contents of each jar were removed, thoroughly air-dried and ground for analysis. A Io-g. portion from each jar was analyzed for humus and humus nitrogen, using the method of Grandeau, as modified by Hilgard. ${ }^{1}$ Table I gives the results obtained.

This table shows that dried and ground kelp in this experiment was decomposed to form humus to approxi-i in which these materials were added to the soil are not the same as would obtain in field practice. None of the materials would be finely ground, with the possible exception of the kelp, if it were part of a complete fertilizer. The alfalfa would ordinarily be plowed under green and the manure moist and fresh: these conditions accelerate their decomposition in the soil. The kelp used in this experiment. as has already been pointed out, was heated to a much greater temperature than would be the case in commercial practice and hence was probably less readily decomposed. The conditions in the laboratory may favor the decomposition of one substance more than another.

The per cent of humus is not necessarily a definite index of the value of the organic matter in the soil. Therefore, it is not desired to convey the impression that the organic matter of kelp is proven by this experiment to be as valuable as the other materials used. The experiment does prove, however, that kelp is not an inert substance in the soil and that its organic matter has some fertilizing value. Final judgment upon these points would require data obtained from field experiments.

\section{PENTOSAN DECOMPOSITION}

Hoagland has shown that kelp contains considerable amounts of pentosans and since the other materials used are also high in pentosans, it is desirable to study the fate of this group in the soil. The materials were

\begin{tabular}{cll} 
& \multicolumn{3}{c}{ MatERIAL } \\
Jars & ADDED \\
1 \& 2 & Alfalfa \\
$3 \& 44$ & Straw \\
$5 \& 6$ & Manure \\
$7 \& 8$ & Nereocystis \\
$9 \& 10$ & Macrocystis \\
$11 \& 12$ & Mac. (inoc.) \\
13 \& 14 & [Blanks]
\end{tabular}

\begin{tabular}{llll}
\multicolumn{4}{c}{ PIR cENT HumUS IN SOIL } \\
Duplicates & AV. & GAIN \\
0.98 & 1.08 & 1.03 & 0.37 \\
1.14 & 1.24 & 1.19 & 0.53 \\
1.08 & 1.11 & 1.10 & 0.44 \\
1.03 & 1.16 & 1.10 & 0.44 \\
0.96 & 1.03 & 1.00 & 0.34 \\
0.98 & 1.06 & 1.02 & 0.36 \\
0.65 & 0.66 & 0.66 & $\ldots$.
\end{tabular}

TABLE I-
$\% \mathrm{~N}$ in
HumLs
10.15
8.25
9.54
10.50
11.55
9.95
13.82

mately the same degree as the substances ordinarily employed for that purpose. On a basis of equal weights of original material, the Nereocystis is surpassed only by straw, is equal to manure and superior to alfalfa. The Macrocystis is somewhat inferior but nearly equal to alfalfa. The inoculation of the Macrocystis slightly increased its humification but not sufficiently to cause it to surpass any of the other materials. The variations in the percentage of nitrogen in the humus are slight and no great importance is attached to them.

Since the various materials used contain very different amounts of organic matter which might be humified, the percentage of the organic matter humified during the period of incubation is important. The per cent of organic matter in the original materials and the average per cent of this organic matter which humified appear in Table I. On the basis of a unit amount of organic matter, the Nereocystis is by far the best humus producer and even the Macrocystis is surpassed only by the manure. The conditions under which this experiment was carried out, viz, constant moisture content of 18 per cent and constant temperature of $30^{\circ} \mathrm{C}$. for 5 mos., would certainly be equivalent to a considerably longer period under field conditions. Furthermore, the form and manner

"Hilgard, "Soils," p. 132.

TESTs
\% Pentosans
in Originals
12.18
27.75
11.57
6.16
7.11
7.11
$\ldots$.

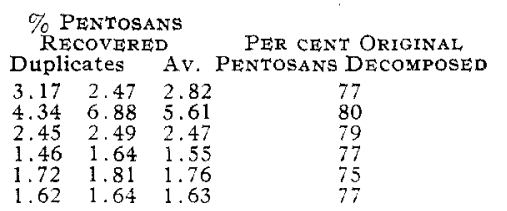

analyzed for pentosans according to the Official method, ${ }^{2}$ which is empirical and depends upon the production of furfurol from whatever source derived; hence, conclusions regarding the decomposition of pentosan materials must be based simply upon comparative data. The samples of soil and organic materials were the same as those previously described. After 5 mos. incubation the soils were analyzed and the percentages of pentosans found calculated to the original weight of materials added to the soil. Tests on untreated soil showed only very small amounts of furfurol-yielding substances, and corrections were made for the blanks. The extent of decomposition in each case is given in Table I. It is evident that the pentosans in the different materials are all decomposed to about the same extent, since in all cases between 75 and 80 per cent of the total amount has been decomposed regardless of the original source or amount. Some slight differences which are evident can be reconciled with previously established facts, e.g., it is known that Nereocystis is more easily decomposed than Macrocystis; inoculation slightly increased the decomposition of Macrocystis. These data also indicate that from the standpoint of pentosan decomposition, kelp may be ranked with the other materials tested.

1 "Organic Constituents of Pacific Coast Kelps," J. Agr. Res., 4, No. $1(1915), 39$

2Bureau of Chemistry, L. S. Dept. Agr., Bull. 107, 54. 


\section{SLMMARY}

Dried and ground kelp decomposes in the soil under laboratory conditions, increasing the humus content to an extent comparable with alfalfa, manure and straw. Of the pentosans present, 75 to 80 per cent was decomposed in all the materials.

Acknowledgment is made to Professor D. R. Hoagland, at whose suggestion the above work was performed.

Agricultural Experiment Station

UNIVERSITY OF CALIFORNIA, BERKELEX

\section{ESTIMATION OF CARBON DIOXIDE AS BARIUM CAR- BONATE APPLIED TO THE MARR METHOD FOR DETERMINATION OF CARBON- ATES IN SOIL}

By C. J. Schollengerger

Received December 27, 1915

Closely following the publication by Marr ${ }^{1}$ of a method for soil carbonates, a modification embodying its essential features, which are evolution of carbon dioxide by boiling with dilute acid under reduced pressure and absorption of the evolved carbon dioxide in a solution of sodium hydroxide, the carbonate therein being subsequently estimated by the well-known double titration method of Brown and Escombe, ${ }^{2}$ was extensively studied in this laboratory and a form of apparatus adapted to it subsequently described by E. W. Gaither. ${ }^{3}$

Extended experience with this method, both in every-day use on routine samples and with the special samples furnished by the Referee on Soils for the Association of Official Agricultural Chemists' work in IgI4 and I9I5, has served to establish the fact that the decomposition of soil at a moderate temperature in vacuo by dilute hydrochloric acid is undoubtedly the most accurate of all procedures so far proposed for this determination, as it reduces to a minimum the activity of acid on organic material. When the soil is treated with acid in the cold there will be for some samples, depending on the nature of the carbonates present, an incomplete decomposition of carbonate. If the soil be boiled at atmospheric pressure with acid there will be an excessive action on the organic matter with consequent liberation of carbon dioxide not derived from carbonates, necessitating a blank determination on an extracted sample and the application of a correction for carbon from organic sources which involves considerable uncertainty.

There is, however, a source of error in the Marr method if the double titration procedure is used for determining the evolved carbon dioxide. This is indicated by the fact that the results by the Marr method, although showing excellent agreement with those obtained by boiling with stronger acid, the proper correction being applied and the double titra-. tion procedure used in each case, do not show such good agreement when compared with results obtained by boiling at atmospheric pressure and measuring the carbon dioxide gas, the corresponding correction

\footnotetext{
1 Jour. Agr. Science, [2] 3, 155

2 Phil. Trans. (B), 193 (1900), 289

3 This Journal, 4 (1912), 611 .
}

for action of acid on organic matter being applied. Nor is it usually found possible to recover by the double titration method all the carbon dioxide from samples of pure carbonates.

As the result of work done in this laboratory, and having for its object the improvement of the Marr method and at the same time the retention of its essential feature, which is decomposition of soil carbonates by dilute acid at reduced pressure and tem. perature, involving the least possible attack upon soil organic matter which is compatible with complete decomposition of carbonates and complete evolution of the gaseous carbon dioxide in the minimum period of time, it has been found possible to do away with the objectionable double titration. This is accomplished by effecting the absorption of the carbon dioxide evolved from the sample in barium hydroxide solution contained in a Meyer bulb tube. The precipitated barium carbonate is filtered off and determined as described by Cain. ${ }^{1}$ The method is essentially the same as that recommended for adoption as a tentative method by the Referee on Soils of the Association of Official Agricultural Chemists in $19 \mathrm{r}_{5}$.

E. Truog ${ }^{2}$ has described a method for the determination of carbon dioxide by absorption in a meas ured excess of barium hydroxide solution and titration of the excess of barium hydroxide, using phenolphthalein as indicator. A trial was made of this method also, but effecting the absorption in a Meyer bulb tube, which seemed to be better adapted to the purpose in this instance than did the ingenious bead tower described by Truog. The results were satisfactory when the acid used for the titration was standardized by the use of a sample of known carbonate content, as pointed out by Brady. ${ }^{3}$ If the theoretical strength of the acid had been employed in making the calculations, a considerable minus error might have been introduced. The method offers important advantages over the double titration procedure, and will probably give better results in the hands of operators not thoroughly familiar with the latter method, but it must not be forgotten that it is subject to the same great source of error, viz., the presence of substances supposedly neutral to phenolphthalein, but through hydrolysis, alkaline to that indicator-sodium bicarbonate in the one case and barium carbonate in the other.

For the reasons enumerated above, it is evident that absorption in barium hydroxide solution and titration of the residual hydroxide offers only a slight advantage over the older scheme of absorption in sodium hydroxide and double titration on the score of accuracy of results, although it does offer some advantages in the points of speed and convenience. By careful standardization of the method, it would doubtless give satisfactory results for routine work. The filtration method proposed by Cain is not subject to the above sources of error, and should give

1 Technological Paper 33, Bureau of Standards; also This Jotranal, 6 (1914), 465 .

2 This Jotrnal, 7 (1915), 1045.

${ }^{3}$ Ibid., 6 (1914), 843 